\title{
Molecular histology on the diagnostic cutting edge between malignant melanomas and cutaneous melanocytomas (Review)
}

\author{
PASCALE QUATRESOOZ, CLAUDINE PIERARD-FRANCHIMONT, \\ GERALD E. PIERARD and THE MOSAN STUDY GROUP OF PIGMENTED TUMORS \\ Department of Dermatopathology, University Hospital of Liège, Liège, Belgium
}

Received June 2, 2009; Accepted August 5, 2009

DOI: $10.3892 /$ or_00000563

\begin{abstract}
In recent years, the screening accuracy of clinical dermoscopy has increased in the early detection of evolving atypical melanocytic neoplasms. However, the most dramatic cases of human malignant melanomas (MM), i.e. the fastgrowing neoplasms, usually escape the classical clinical criteria of MM. As a result, a number of puzzling cases exhibit uncertain clues for MM. Thus, the risk of microscopic misdiagnosis is likely on the rise if the histological criteria are not fine-tuned. This review summarizes a conceptual classification of atypical melanocytic neoplasms grouped under the heading of melanocytomas. Some immunohistochemical markers are tentatively used as discriminators between fast-growing MM and melanocytomas. However, some differences seem to be more statistically significant than clinically useful due to extensive overlap in immunoreactivity from any case to case. A multipronged immunohistological screening is therefore welcome.
\end{abstract}

\section{Contents}

1. Introduction

2. Histological distinction between atypical melanocytic neoplasms

3. Triggered melanocytic naevi and cutaneous melanocytomas

4. Phenotypic presentations of cutaneous melanocytomas

5. Growth fraction, proliferation and apoptosis in cutaneous melanocytomas

6. Microvasculature in cutaneous melanocytomas

7. Microscopic satellites

8. Conclusion

Correspondence to: Professor Gérald E. Piérard, Department of Dermatopathology, CHU Sart Tilman, BE-4000 Liège, Belgium E-mail: gerald.pierard@ulg.ac.be

Key words: malignant melanoma, melanocytoma, immunohistochemistry, cell proliferation

\section{Introduction}

Over the past decades, the worldwide incidence of human malignant melanoma (MM) has considerably increased in Caucasian populations (1-4). In this perspective, there is growing need to improve diagnostic procedures supporting early treatment and decreasing MM morbidity and mortality.

Currently, MM is in part classified according to its clinical growth rate. Fast-growing MM are typically characterized by a vertical growth pattern. They have a worse prognosis compared to slow-growing MM which are commonly confined superficially (5-7). In fact, this concept is related to the histological distinction between the radial (superficially spreading) MM and the vertical growth phase (invasion of the dermis).

\section{Histological distinction between atypical melanocytic neoplasms}

In clinical practice a clear-cut distinction is required between benign and malignant melanocytic neoplasms (8-10). In most instances, the histological diagnosis of $\mathrm{MM}$ is straightforward for experts in the field $(11,12)$. MM are commonly classified according to the total thickness in millimeters, the mitotic activity, the presence of ulceration, the penetration depth, and the identification of metastases (13). However, due to the wide spectrum of histological features the situation may occasionally appear ambiguous $(11,12)$. For instance, in small size melanocytic lesions, all the classical histological criteria for borderline MM or undisputable MM are not always met, or they fail to make the distinction confidently. Those neoplasms are tentatively classified in a spectrum going from 'benign' to 'not-so-benign', 'not-so-malignant', and 'malignant' (10). In the literature, the two intermediate categories are variously referred to as melanocytomas, melanocytic dysplasias, minimal deviation melanomas, borderline melanomas, melanocytic tumors of uncertain malignant potential (MELTUMP) and spitzoid melanocytic tumors of uncertain malignant potential (STUMP) (10,14-22).

Although conventional histology is the mainstay for diagnosing atypical melanocytic neoplasms, clinical features, in particular the dermoscopic aspects remain of central importance. Cutaneous melanocytoma in its strict etymological sense, refers to benign tumor of melanocytes $(10,14)$. This term encompasses melanocytic neoplasms which do not meet 
the classical histological criteria of any type of common melanocytic naevi and MM $(10,18,21,22)$. They often develop singly but occasionally, multiple melanocytomas occur. Some of these lie grouped together (agminate type) and potentially recur after removal of a solitary lesion (23). The term melanocytoma is similarly used in other fields of human pathology (leptomeninges, eye) and animal pathology (skin) for distinguishing peculiar and usually benign melanocytic neoplasms $(24,25)$.

The recognition of the 'newer' intermediate set of atypical melanocytic neoplasms and a better molecular staging of MM types has benefited in recent years from progress in immunohistochemistry $(9,10,15,18,26-31)$. Using such an approach, most uncommon MM variants are also identified with confidence $(9,17,19,32)$. It is acknowledged that MM molecular alterations and their respective immunological responses accompany the neoplastic progression from incipient to advanced stages $(9,18)$. In this field, it is possible to use markers of proliferation, melanocytic differentiation and immunomodulation. In addition, the identification of signalling molecules, nerve growth factors and receptors is potentially useful, particularly in spindle cell variants of MM.

\section{Triggered melanocytic naevi and cutaneous melano- cytomas}

In a series of endogenous and exogenous conditions, melanocytic naevi are triggered and they may appear as melanocytomas. Some specific internal messages and environmental factors have been identified in this field. Examples are melanocytomas developed on congenital naevi, dysplastic naevi (33), naevi modified by pregnancy or oral contraception (34), naevi of subjects on growth hormone therapy (15), naevi under ultraviolet-light irradiation $(35,36)$. It should be mentioned that some of these lesions mimick MM or are at risk for MM development (37). The possibility of a melanocytoma should be evoked in each single case. In this review, the term melanocytoma encompasses a broad category of melanocytic neoplasms that can further be distinguished according to the identified origins and the clinico-pathological confrontation.

Globally, the melanocytoma class is histologically recognized by the combination of some criteria including architectural disorganisation and asymmetry, discrete nuclear atypia and anisokaryocytosis as well as the eventual juxtaposition of an ancillary focal or diffuse inflammatory cell reaction (10). However, the variable combination and extent of such signs in different lesions preclude establishing any straightforward set of major criteria identifying distinct specific subsets of melanocytomas, with, however, the exception of the common type of Spitz melanocytoma (naevus) (10).

Another special type of melanocytoma presents as an atypical dermal nodule in an otherwise normal-looking melanocytic naevus. Such atypical nodules may suggest an intralesional transformation recognized by some pathologists as a sign of malignancy, although it does not exhibit other features of aggressive behaviour. The increase in size of this type of melanocytic lesion is mainly due to more abundant, pale cytoplasm in each individual cell. The nuclei show only a marginal increase in size and do not exhibit pleomorphism. There may be invagination of the nucleus by cytoplasm, giving a vacuolated appearance. Mitoses are hardly ever seen.

After excluding the pregnancy-related changes in melanocytic lesions, the overall melanocytoma gender ratio $(\mathrm{F} / \mathrm{M})$ reaches $1.6(10)$. The age distribution is similar in both gender groups. The prevalence of all melanocytomas peaks during the 3rd and 4th decades of life and a sharp decrease occurs after the age of 50 years on. Such age and gender distributions resemble that of MM $(2,4)$.

The distinction between melanocytomas and MM ideally expects that all members of each group behave either completely benign or fully malignant. This concept probably does not fully hold true. The variability in the histological presentations of MM and melanocytomas poses diagnostic difficulties and the clinical attributes may remain disturbing. Any error in this differential diagnosis has profound consequences including mutilating overtreatment or, conversely, life-threatening undertreatment. At the present time, controversies exist as to the diagnoses to be given for certain neoplasms and their predictive evolution leading to potential implication in legal liability (38).

\section{Phenotypic presentations of cutaneous melanocytomas}

Some differentiation markers are routinely used when facing an atypical melanocytic neoplasm $(9,10,18,26)$. Immunohistochemistry is used as an adjunct for distinguishing MM and melanocytomas or other neoplasms. The common antibodies are directed to the S100 protein, the gp100/HMB45, the melan A/MART-1, the CD63/NKi-C3 and tyrosinase.

The $\mathrm{S} 100$ protein is a $21 \mathrm{kDa}$ acidic calcium-binding protein which is abundant in the nucleus and cytoplasm of melanocytic cells. HMB45 is a marker of the cytoplasmic premelanosomal glycoprotein gp100. The melanoma antigen recognized by T-cells-1 (MART-1) is similar to Melan-A. The CD63/NKi-C3 is a $25-110 \mathrm{kDa}$ glycoprotein located on the inner membrane of cytoplasmic vesicles in melanocytes. Tyrosinase is an enzyme that hydrogenates tyrosine in the process of melanin synthesis.

In general, the common benign melanocytic neoplasms are structured in an orderly manner showing symmetry and so-called maturation with deeper location of smaller cells toward the base of the lesion. The immunohistochemical labelling of differentiation markers including S100 protein and melan-A is often intense, diffuse and uniform in these lesions and in most melanocytomas as well (18). Tyrosinase immunoreactivity decreases toward the base of most melanocytomas.

In benign melanocytic naevi, the HMB-45 and CD63 immunoreactivities are negative or restricted to the superficial part of the lesions inside the papillary dermis. Some lesions show trailing off with progressive descent in the deeper portion of the melanocytic naevus. These two markers are quite often expressed in tandem in melanocytomas. Lateral asymmetry and spotty or patchy patterns of immunohistochemical differentiation are typically found in MM and in melanocytomas including MELTUMP and STUMP $(10,18,19,27)$. According to the antibody, the immunohistochemical pattern may be diffuse throughout the melanocytomas. 
In general, the sensitivity of the differentiation markers decreases or becomes heterogeneous in MM with increasing clinical stage including metastatic lesions (39). Such a feature is not found with maturation of melanocytomas. It should be mentioned that immunohistochemistry proved to be very useful in tracking MM microsatellites (40) which are predictors of sentinel lymph node metastases and relapse-free survival (41).

\section{Growth fraction, proliferation and apoptosis in cutaneous melanocytomas}

The disturbance of autonomous growth regulatory pathways in melanocytomas and MM appears to be of prime importance. Earlier observations relied on the assessment of the number of mitotic figures and AgNOR (Nuclear Organizing Region) staining. This proved to be fastidious giving only a rough estimate of the proliferative rate. Mitoses observed in the deepest parts of the melanocytic neoplasm appeared to have greater significance for MM diagnosis than those more superficially located. However, there were no absolute thresholds for the mitotic index being indicative of malignancy. Atypical tripolar mitotic figures were indicative for MM rather than melanocytomas.

Twenty-five years ago, a breakthrough was obtained using autoradiography after incorporation of tritiated thymidine (42). A correlation was found between the ${ }^{3} \mathrm{H}-\mathrm{TdR}$ labelling index and the MM thickness. Metastases remained with a high immunolabelling index while benign melanocytic lesions showed a very low proportion of cells in $\mathrm{S}$ phase. As the radioautography procedure was almost impossible to apply routinely, the method was switched to the PCNA and Ki67 immunolabellings which brought similar information. There are two clinical applications for which these markers have been studied, namely the distinction of melanocytic naevi from MM and the assessment of clinical prognosis for patients with MM.

The most widely used proliferation marker is Ki67, a nuclear antigen present in all active phases of cell cycle proliferation $\left(G_{1}, S, G_{2}\right.$ and $\left.M\right)$, but absent in the quiescent phase (G0). Ki67 immunolabelling has been shown to be positive in $<5 \%$ of cells in most melanocytic naevi. Up to $15 \%$ positivity may be found in melanocytomas $(10,43-47)$. The quantitative loss of Ki67 expression with depth correlates with maturation and less atypical lesions $(19,48)$. A brisk mitotic rate or Ki67 index is not a common feature of melanocytomas, but rather suggests MM. Most thin MM appear to be in a growth-stunted phase exhibiting an accretive rather than proliferative formation of nests. Thicker MM and their metastases have a higher Ki67 index. On the overall, the Ki67 index reaches $15-30 \%$ of MM cells although some individual cases show much more nuclear positivity. The Ki67 index alone is not a reliable discriminator between $\mathrm{MM}$ and melanocytomas when it ranges in the overlap 10-20\%. The presence of MM stem cells (low Ki67 index) (49) and clonal events (50) further complicate the process (51).

In our experience, the Ki67 index of keratinocytes is often higher than that of tumoral cells in melanocytomas. The reverse situation is seen in MM thicker than $0.4 \mathrm{~mm}$.

Apoptosis is quite different from necrotic cell death and represents one major mechanism involved in reducing the expansible growth of melanocytic neoplasms. As a functional counterpart of mitosis, apoptosis plays a crucial role and is normally firmly regulated. Apoptosis is deranged in melanocytic neoplasms when the components and regulators of the cellular apoptotic machinery are mutated or present in inappropriate amounts. The pro-apoptotic factors include Bax, Bid, Fas/FasL, IFN, c-Kit/SCF, Noxa, p53, PITSLRE, PUMA, TNF and TRAIL. The anti-apoptotic factors include Bcl-2, Bcl-XI, livin, Mcl-1, ML-LAP, NFкB and survivin. Alternatively, other molecules including endothelins, integrins, c-Myc and TRAF-2 may show either pro- or anti-apoptotic effects (52).

Apoptosis may appear quite active in melanocytomas. The so-called Kamino bodies in Spitz melanocytoma likely result from such a process. At present the complex machinery of apoptosis has not been thoroughly studied in melanocytomas.

\section{Microvasculature of cutaneous melanocytomas}

In thin MM, the microvascular density shows a wide range of development among distinct lesions. An overall stochastic relationship appears to be present between the microvasculature size and the size of the germinative compartment.

Microvessels have been reported to be fewer in melanocytomas than in MM. The vascular endothelial growth factor (VEGF) is frequently detectable in MM, contrasting with the usual negativity in melanocytomas (10).

The extent of angiogenesis may help in distinguishing melanocytomas from MM (10). However, it should be noted that some growth-stunted MM show weak angiogenesis (53). Conversely, angiomatoid melanocytomas have been described (54-57). Therefore, the differences in MM and melanocytoma angiogenesis seem to be more statistically significant than clinically useful due to the extensive overlap in extent from any case to case.

\section{Microscopic satellites and MM stem cells}

The definition of malignancy is disputed in the field of melanocytic neoplasms. Indeed, distant locations including nodal infiltration by melanocytic cells is not synonymous with a metastatic spread. There may be melanocytomas, particularly with a spitzoid aspect, that do not remain confined to the primary site. They exhibit the propensity to spread regionally in the skin (agminate type) and in the lymph nodes, but do not reach more distant sites. The interpretation of regional spread is subject to controversy. Some authors regard it as formal proof of malignancy and consider the secondary lesions as satellitosis or in-transit metastases (40). Others argue that this stance constitutes an over-interpretation. Nonetheless, it appears that the regional cutaneous and nodal spread of melanocytomas neither equals distant metastasis nor constitutes sufficient proof of malignancy. All these considerations are relevant in orienting the choice of systemic therapy for metastatic MM (58).

It is possible that cells at the origin of these distant locations in MM and melanocytomas are different in nature. MM stem cells are possibly involved in MM metastases $(59,60)$. By contrast, melanocytoma satellitosis do not apparently involve stem cells. 


\section{Conclusion}

Melanocytic neoplasms of the skin are heterogeneous in nature and in aspect. A vast number of genetic changes are described in malignant melanoma, but the primary ones are not clearly defined. Melanocytomas represent benign melanocytic neoplasms showing atypical features at the histological inspection. However, there is no single criterion defining melanocytomas. The distinction between malignant melanoma and melanocytomas is of utmost importance for the management of patients. The combination of moderately increased cell proliferation and heterogeneous patchy differentiation is a clue for melanocytomas irrespective of their type. Most melanocytomas appear to result from the effect of some internal or extrinsic triggering factors.

Traditional classification systems for MM have centered on clinicopathological correlations. Although some particular MM subtypes are clinically and histologically distinct, a wealth of studies indicates that current parameters for classification are without independent prognostic value. Indeed, some markers of potential clinical utility looking promising in small-scale studies fail to prove clinically useful in larger-scale studies. Such disappointing features appear to stem from the heterogeneous nature of MM during its evolution. A vast number of molecular changes are indeed present in advanced MM compared with melanocytes. Various mutations are disclosed from comparative gene expression profiling of MM from different stages. It is difficult to sort out which are central to malignancy and typical for MM. In the wide range of molecular changes it is therefore difficult to sharply define when a given melanocytic neoplasm becomes malignant. In this context, melanocytomas are part of an evolving paradigm for classifying melanocytic neoplasms.

Melanocytomas form an intermediate category of melanocytic neoplasms between common naevi and MM. They behave as benign lesions but their histological presentations may be troublesome or worrying. Immunohistochemistry evaluating differentiation markers and proliferation markers helps distinguishing melanocytomas from MM. A multipronged immunohistochemical analysis should be performed in order to reach a high level of diagnostic accuracy.

We underscore recent studies that have provided insights into the diversity of melanocytic neoplasms. We expect these studies and subsequent analogous studies will inform the melanoma research community and the dermatologist, and provide novel ways to manage patients with atypical melanocytic neoplasms.

\section{Acknowledgements}

The members of the Mosan Study Group of Pigmented Tumors are Drs J.E. Arrese, G. Blaise, R. Bourguignon, C. Braham, M. Broux, N. Claessens, F. Cornil, M. Dameaux, J.M. Darcis, J. Dehavay, P. Delvoye, C. Devillers, A.L. Fraiture, C. Franchimont, I. Fumal, V. Goffin, F. Henry, J.F. Hermanns, T. Lê, M. Lesuisse, C. Letawe, B. Letot, O. Martalo, F. Mauhin, A. Nikkels, P. Paquet, G.E. Piérard, P. Quatresooz, G. Szepetiuk, N. Tassoudji, L. Thirion, I. Uhoda, G. Vandenbossche and V. Willemaers. This work was supported by a grant from the 'Fonds d'Investissement de la Recherche Scientifique' of the University Hospital of Liège. No other sources of funding were used to assist in the preparation of this manuscript. The authors appreciate the excellent secretarial assistance of I. Leclercq.

\section{References}

1. Jemal A, Devesa SS, Hartge P and Tucker MA: Recent trends in cutaneous melanoma incidence among whites in the United States. J Natl Cancer Inst 93: 678-683, 2001.

2. Quatresooz P, Uhoda I, Fumal I, Piérard-Franchimont C and Piérard GE: Revisiting the gender-linked melanoma burden. Dermatology 209: 197-201, 2004.

3. Thompson JF, Scolyer RA and Kefford RF: Cutaneous melanoma. Lancet 365: 687-701, 2005.

4. Uhoda I, Quatresooz P, Fumal I, Nikkels AF, PiérardFranchimont $\mathrm{C}$ and Piérard GE: Updating trends in cutaneous cancers in south-east Belgium. Oncol Rep 12: 111-114, 2004.

5. Lipsker D: Growth rate, early detection and prevention of melanoma: melanoma epidemiology revisited and future challenges. Arch Dermatol 142: 1638-1640, 2006.

6. Liu W, Dowling JP, Murray WK, McArthur GA, Thompson JF, Wolfe R and Kelly JW: Rate of growth in melanomas: characteristics and associations of rapidly growing melanoma. Arch Dermatol 142: 1551-1558, 2006.

7. Liu W, Kelly JW, Trivett M, Murray WK, Dowling JP, Wolfe R, Mason G, Magee J, Angel C, Dobrovic A and McArthur GA: Distinct clinical and pathological features are associated with braf mutation in primary melanoma. J Invest Dermatol 127: 900-905, 2007.

8. Quatresooz P, Piérard-Franchimont C and Piérard GE: Spacetime clustering and seasonality in diagnosing skin cancers in wallonia (south east Belgium). Dermatology 217: 48-51, 2008.

9. Ohsie SJ, Sarantopoulos GP, Cochran AJ and Binder SW: Immunohistochemical characteristics of melanoma. J Cutan Pathol 35: 433-444, 2008.

10. Quatresooz P, Piérard-Franchimont C and Piérard GE: Highlighting the immunohistochemical profile of melanocytomas. Oncol Rep 19: 1367-1372, 2008.

11. Banerjee SS and Harris M: Morphological and immunophenotypic variations in malignant melanoma. Histopathology 36: 387-402, 2000.

12. Smoller BR: Histologic criteria for diagnosing primary cutaneous malignant melanoma. Mod Pathol 19: S34-S40, 2006.

13. Chin L: The genetics of malignant melanoma: lessons from mouse and man. Nat Rev Cancer 3: 559-570, 2003.

14. Ainsworth AM, Folberg R, Reed RJ and Clark WH: Melanocytic nevi, melanocytomas, melanocytic dysplasias, and uncommon forms of melanoma. In: Human Malignant Melanoma, Clinical Oncology Monographs. Clark WH, Goldman KI and Mastrangelo MJ (eds). Grune \& Straaton, New York, pp167-208, 1979.

15. Piérard GE, Piérard-Franchimont C, Nikkels AF, NikkelsTassoudji N, Arrese JE and Bourguignon JP: Naevocyte triggering by recombinant human growth hormone. J Pathol 180: 74-79, 1996.

16. Gurbuz Y, Apaydin R, Muezzinoglu B and Buyukbabani N: A case report and a current dilemma in histopathology, atypical spitz nevus or spitzoid melanoma. Pediatr Dermatol 19: 99-102, 2002.

17. Cook MG: Diagnostic pitfalls with melanocytic tumours. Curr Diagn Pathol 10: 463-472, 2004.

18. Quatresooz P, Arrese JE, Piérard-Franchimont C and Piérard GE: Immunohistochemical aid at risk stratification of melanocytic neoplasms. Int J Oncol 24: 211-216, 2004.

19. Barnhill RL: The spitzoid lesion, rethinking spitz tumors, atypical variants, 'spitzoid melanoma' and risk assessment. Mod Pathol 19: S21-S33, 2006.

20. Lee JB: Spitz nevus versus melanoma, limitation of the diagnostic methodology exposed. Eur J Dermatol 16: 223-224, 2006.

21. Zembowicz A, Carney JA and Mihm MC: Pigmented epithelioid melanocytoma: a low-grade melanocytic tumor with metastatic potential indistinguishable from animal-type melanoma and epithelioid blue nevus. Am J Surg Pathol 28: 31-40, 2004. 
22. Fraitag S and Vignon-Pennamen MD: Spitz tumor and pigmented epithelioid melanocytoma: new nosological frameworks for commonly ill-defined tumors. Ann Dermatol Venereol 136: 133-144, 2009.

23. Sabroe RA, Vaingankar NV, Rigby HS and Peachey RD Agminate spitz naevi occurring in an adult after the excision of a solitary spitz naevus, report of a case and review of the literature. Clin Exp Dermatol 21: 197-200, 1996.

24. Turhan T, Oner K, Yurtseven T, Akalin T and Ovul I: Spinal meningeal melanocytoma: report of two cases and review of the literature. J Neurosurg 100: 287-290, 2004.

25. O'Brien DF, Crooks D, Mallucci C, Javadpour M, Williams D, du Plessis D, Broome J, Foy P and Pizer B: Meningeal melanocytoma. Childs Nerv Syst 22: 556-561, 2006.

26. Mangni J, Li N and Bhawan J: Immunohistochemical markers of melanocytic lesions: a review of their diagnostic usefulness. Am J Dermatopathol 24: 270-281, 2002.

27. Alonso SR, Ortiz P, Pollan M, Pérez-Gomez B, Sanchez L, Acuna MJ, Pajares R, Martinez-Tello FJ, Hortelano CM, Piris MA and Rodriguez-Peralto JL: Progression in cutaneous malignant melanoma is associated with distinct expression profiles: a tissue microarray-based study. Am J Pathol 164: 193-203, 2004

28. Quatresooz P and Piérard GE: Immunohistochemical investigation of $\alpha 1$ (IV) and $\alpha 5$ (IV) collagen chains in a broad spectrum of melanocytic tumours. Melanoma Res 15: 161-168, 2005.

29. Fecher LA, Cummings SD, Keefe MJ and Alani RM: Toward a molecular classification of melanoma. J Clin Oncol 25: 1606-1620, 2007.

30. Plaza JA, Suster D and Perez-Montiel D: Expression of immunohistochemical markers in primary and metastatic malignant melanoma, a comparative study in 70 patients using a tissue microarray technique. Appl Immunohistochem Mol Morphol 15: 421-425, 2007

31. Webber A, Lawson D and Cohen C: Maspin and mutant p53 expression in malignant melanoma and carcinoma, use of tissue microarray. Appl Immunohistochem Mol Morphol 16: 19-23, 2008.

32. Quatresooz P, Piérard-Franchimont C and Piérard GE: Diagnostic challenge of desmoplastic melanoma. Trends Cancer Res 3: 27-34, 2007.

33. Piérard GE and Al Rustom K: Dysplastic nevi and the concept of triggered melanocytic system. Emerg Med J 7: 3-6, 1989.

34. Aktürk AS, Bilen N, Bayrämgürler D, Demirsoy EO, Erdogan S and Kiran R: dermoscopy is a suitable method for the observation of the pregnancy-related changes in melanocytic nevi. J Eur Acad Dermatol Venereol 21: 1086-1090, 2007.

35. Tronnier $\mathrm{M}$ and Wolff $\mathrm{H}$ : UV-irradiated melanocytic nevi simulating melanoma in situ. Am J Dermatopathol 17: 1-6, 1995.

36. Brozyna A, Zbytek B, Granese J, Carlson JA, Ross J and Slominski A: Mechanism of UV-related carcinogenesis and its contribution to nevi/melanoma. Exp Rev Dermatol 2: 451-469, 2007.

37. Beyeler M, Hafner J, Beinder E, Fauchêre JC, Stoeckli SJ, Fehr M and Dummer R: Special considerations for stage IV melanoma during pregnancy. Arch Dermatol 141: 1077-1079, 2005.

38. Brochez L, Verhaeghe E, Grosshans E, Haneke E, Piérard G, Ruiter D and Naeyaert JM: Inter-observer variation in the histopathological diagnosis of clinically suspicious pigmented skin lesions. J Pathol 196: 459-466, 2002.

39. Orchard GE: Comparison of immunohistochemical labelling of melanocyte differentiation antibodies melan-A, tyrosinase and HMB45 with NKIC3 and S100 protein in the evaluation of benign naevi and malignant melanoma. Histochem J 32: 475-481, 2000.

40. Claessens N, Piérard GE, Piérard-Franchimont C, Arrese JE and Quatresooz P: Immunohistochemical detection of incipient melanoma micrometastases: relationship with sentinel lymph node involvement. Melanoma Res 15: 107-110, 2005.
41. Shaikh L, Sagebiel RW, Ferreira CM, Nosrati M, Miller JR III and Kashani-Sabet M: The role of microsatellites as a prognostic factor in primary malignant melanoma. Arch Dermatol 141: 739-742, 2005.

42. Piérard GE, Piérard-Franchimont C, Henry $\mathrm{C}$ and Lapière M: The proliferative activity of cells of malignant melanomas. Am J Dermatopathol 6: S317-S324, 1984.

43. Soyer HP: Ki67 immunostaining in melanocytic skin tumors. correlation with histologic parameters. J Cutan Pathol 18: 264-272, 1991

44. Piérard-Franchimont C, Arrese JE, Nikkels AF, Al-Saleh W Delvenne P and Piérard GE: Factor XIIa-positive dermal dendrocytes and proliferative activity of cutaneous cancers. Virchows Arch 429: 43-48, 1996.

45. Li LX, Crotty KA, Mccarthy SW, Palmer AA and Kril JJ: A zonal comparison of MIB1-Ki67 immunoreactivity in benign and malignant melanocytic lesions. Am J Dermatopathol 22: 489-495, 2000

46. Bergman R, Malkin L, Sabo E and Kerner H: MIB-1 monoclonal antibody to determine proliferative activity of Ki67 antigen as an adjunct to histopathologic differential diagnosis of Spitz nevi. J Am Acad Dermatol 44: 500-504, 2001.

47. Vollmer RT: Use of bayes rule and MIB-1 proliferation index to discriminate spitz nevus from malignant melanoma. Am J Clin Pathol 122: 499-505, 2004

48. Kapur P, Selim MA, Roy LC, Yegappan M, Weinberg AG and Hoang MP: Spitz nevi and atypical spitz nevi/tumors, a histologic and immunohistochemical analysis. Mod Pathol 18: 197-204, 2005.

49. Schattton $\mathrm{T}$ and Frank MH: Cancer stem cells and human malignant melanoma. Pigment Cell Melanoma Res 21: 39-55, 2008.

50. Bennett DC: How to make a melanoma: what do we know of the primary clonal events? Pigment Cell Melanoma Res 21: 27-38, 2008.

51. Quatresooz P, Piérard GE, Piérard-Franchimont C and the Mosan Study Group of Pigmented Tumors: Molecular pathways supporting the proliferation staging of malignant melanoma (Review). Int J Mol Med 24: 295-301, 2009.

52. Hussein MR, Haemel AK and Wood GS: Apoptosis and melanoma: molecular mechanisms. J Pathol 199: 275-288, 2003.

53. Piérard GE and Piérard-Franchimont C: Stochastic relationship between the growth fraction and vascularity of thin malignant melanomas. Eur J Cancer 33: 1888-1892, 1997.

54. Piérard-Franchimont $\mathrm{C}$, Henry F, Heymans $\mathrm{O}$ and Piérard GE: Vascular retardation in dormant growth-stunted malignant melanomas. Int J Mol Med 4: 403-406, 1999.

55. Marcoval J, Moreno A, Graells J, et al: Angiogenesis and malignant melanoma: angiogenesis is related to the development of vertical (tumorigenic) growth phase. J Cutan Pathol 24: 212-218, 1997.

56. Heymans O, Blacher S, Brouers F and Piérard GE: Fractal quantification of the microvasculature heterogeneity in cutaneous melanoma. Dermatology 198: 212-217, 1999.

57. Diaz-Cascajo C, Borghi S and Weyers W: Angiomatoid spitz nevus, a distinct variant of desmoplastic spitz nevus with prominent vasculature. Am J Dermatopathol 22: 135-139, 2000.

58. Lorigan P, Eisen T and Hauschild A: Systemic therapy for metastatic malignant melanoma: from deeply disappointing to bright future? Exp Dermatol 17: 383-394, 2008.

59. Klein WM, Wu BP, Zhao S, Wu H, Klein-Szanto AJ and Tahan SR: Increased expression of stem cell markers in malignant melanoma. Mod Pathol 20: 102-107, 2007.

60. Schatton T, Murphy GF, Frank NY, Yamaura K, WaagaGasser AM, Gasser M, Zhan Q, Jordan S, Duncan LM, Weishaupt C, Fuhlbrigge RC, Kupper TS, Sayegh MH and Frank MH: Identification of cells initiating human melanomas. Nature 451: 345-349, 2008. 